\title{
Trampas genéticas y prácticas de la visibilización Discusiones de una imagen política del feto
}

\author{
The Foetus Images: \\ between Genetic Studies and Feminist Aesthetics
}

\author{
Jorge Díaz Fuentes \\ Doctor (c) Universidad de Chile \\ jbdiazf@ciq.uchile.cl
}

\begin{abstract}
SÍNTESIS
Centrarnos en la imagen política del feto es trabajar en un terreno que está atravesado por discursos éticos, lecturas genéticas y posicionamientos politicos. Este texto cuestiona desde la estética de la fotografía, la teoría feminista y los análisis genéticos, qué es lo que muestran las imágenes de fetos exhibidas en pantallas reproducidas a nivel mundial y las respuestas éticas que estas "ecografías" podrían tener sobre quien las observa. Se desarrolla, a su vez un análisis de la eritroblastosis fetal comprendiendo los contextos científico/sociales que dieron origen a la enunciación de esta patología, releyendo con ella los principios de Ontogenia y Filogenia que Ernest Haeckel instauró en el siglo XIX. Este trabajo aborda la imagen política del feto, las valoraciones sociales que esto acarrea y las lecturas genéticas que se entrelazan en todo discurso biológico.
\end{abstract}

\begin{abstract}
Focusing on the political image of the fetus is working on land that is crossed by ethical discourses, readings genetic and political positions. This text questions from the aesthetics of photography, feminist theory and genetic studies, what the images show fetuses displayed on screens worldwide reproduced and ethical responses to these "scans" would have on the onlooker. It develops, in turn an analysis of fetal erythroblastosis comprising scientific contexts / social that led to the enunciation of this condition, re-reading her the principles of Ontogeny and Phylogeny Ernest Haeckel introduced in the nineteenth century. This paper addresses the political image of the fetus, social assessments and readings that carries genetic intertwine throughout biological discourse.
\end{abstract}

Palabras clave: Feto, imagen, feminismo, genética.

Keywords: Fetus, feminism, genetics, image. 
El discurso biológico que se incuba en las prácticas sociales acerca de la maternidad está asociado principalmente a observar cómo la madre construye dentro de sí al feto. Medidas gubernamentales, prácticas médicas y cierto feminismo tradicional centran completamente su foco de atención en observar a las mujeres ${ }^{1}$ como centro de disputas entre lo que se expulsa y lo que se anida durante el embarazo. Se genera un imaginario de la mujer como una barrera selectiva y semipermeable donde estrictos mecanismos de control regulan los intercambios entre un medio "externo" y un "interior" fisiológico. Un mosaico fluido donde no solo está en juego un equilibrio somático y un balance orgánico, sino cierto terreno de derechos. Todo esto para comprender de qué forma el embrión comienza a desarrollarse, a crecer y aferrarse cada vez con más fuerza a las paredes carnosas de un útero, que si no fuera por la implantación del cigoto, se desgarraría sangrando en su supuesto rito mensual.

De esta manera, importa saber cómo el feto crece hasta hacerse parte del cuerpo gestante como un tejido más dentro de él, una parte de su estructura. Es decir, lo que está en el foco de la atención y disputa es una célula totipotente que tiene la capacidad de desarrollarse, proliferar y comprometerse a crear tejidos en un contexto que no le es propio, o mejor dicho, en un nicho que aún no conoce, donde aún no ha establecido conexiones, donde aún no se relaciona. Podemos decir que, sino todos, la mayoría de las interrogaciones, dudas, comentarios o certezas están destinados a comprender cómo -siguiendo el imaginario de lo mítico- es que la madre se come al feto, hasta hacerlo parte de su cuerpo, como un órgano o una prótesis. Pero no como esa prótesis externa, desligada y descorporizada que ciertas prácticas queer enarbolan como fetiche de descentramiento y desnaturalización del sujeto, sino como esa prótesis que "entra en relación directa, y hasta simbiótica, con lo otro de sí: en el sentido específico y literal de que lleva dentro de sí su propio otro. Otro cuerpo -una parte suya- $u$ otro del cuerpo: cosa, artificio, máquina. Un afuera llevado adentro: la prótesis es exactamente eso" (Esposito 2002, 34). Una prótesis de un sujeto que no es ni esencia ni entidad natural puesto que se crea también en cuanto la organogénesis de ese mismo "otro" se anida dentro de sí y con esto entonces lo desnaturaliza al tener esa misma parte ya internalizada. Digamos, absorbida. 
Una ontogenia -siguiendo la filogenética- es siempre solo uno, su historia individual. Así, el que lleva una parte de "otro" dentro de uno -como la prótesis/embrión- rompe con la naturalización ontológica del sujeto al no ser solo uno, sino uno con una parte de "otro" dentro de uno. Con esto quiero decir que una madre con su feto en gestación no sería ontológicamente un sujeto pues rompe con toda esencia de un solo "uno". Digo todo esto para advertir que no es necesario asegurar que lo "otro" en desarrollo (un cigoto, una mórula, un blastocisto) justifique siempre una valoración tal, que el símbolo de la mujer continúe siendo solamente el sustrato para lo que será vida, esto es, vida y al mismo tiempo muerte.

Habría que señalar que, si bien esta deducción permite abrir nuevas formas de comprensión del sujeto ontológico reutilizándolo problemáticamente, no debemos olvidar que estas búsquedas de lo unitario, siempre han tratado de encontrar un solo sujeto, un solo cuerpo mítico, presimbólico y prelingüístico donde la cultura supuestamente incrustaría su acento. Un cuerpo que en nombre de la ciencia adquiere la forma del "ancestro común", como la figura de lo "único" y lo "primigenio" inmune de toda contaminación social. El problema de la búsqueda ansiosa de ese cuerpo original es considerar, en primera instancia, que lo cultural, lo simbólico y lo lingüístico están separados desde un "origen" desechando los entrecruzamientos entre sus diferentes planos. De esta manera, la reconstitución de ese sujeto "único" traería la problemática de considerar que, siempre existió solo "uno", y que lo "otro" solo sería una desviación o una diferencia a ese único cuerpo, a esa unicidad. Urge interponerse críticamente a una epistemología que aún clasifica desde la mirada tradicional de lo "único" que "en conformidad con los patrones dominantes de la cultura occidental (...) reconoce como valor de origen a: el blanco, el hombre, el adulto. Son las formas instituidas de ser sujeto. En consecuencia, son los derechos del hombre, blanco, adulto, los que habrían de extenderse al negro, a la mujer, a los niños, etc." ${ }^{2}$.

Establecer un compromiso con la alteridad como resistencia a una genealogía unitaria con figuras que como nos dice Alejandra Castillo "parecen hablarnos de lo 'absolutamente otro' de lo venido de un lugar aún no descifrado, tal vez de un más allá de lo humano. 
Figuras de la alteridad que de antaño, como sabemos, han estado presentes a la hora de describir a las mujeres" (72).

Comprendo que así han sido las designaciones antropológicas que ven en la mujer solo una matriz enriquecida en nutrientes, reservorio de factores de crecimiento, asignándole una función social sin cuestionar que, antes que cumplir un rol ya designado, existe - precediéndole- una valoración simbólica que habría que cuestionar. Así concibo también las interrogaciones que la teoría feminista contemporánea ${ }^{3}$ quiere sospechar interrumpiendo los supuestos estructurantes de la realidad y su representación de lo "natural". Si las políticas de la interrupción del feminismo que cuestionan finalmente el patrón moderno de la política lo han hecho a través de las estrategias de la ficción, del trabajo de pensar mundos posibles e inapropiables que el lenguaje de la universalidad humanista decreta como menos "real" o menos "efectivo", deberíamos entonces cuestionar también, las formas que adquieren nuestros cuerpos para desaprender sin melancolía, la morfología actual de nuestras identidades "dañándolas". Un proceso de subjetivación sería entonces un des-nudo de la clasificación, de la disciplina que creemos dominar, de la mirada con que nos miran y nos miramos.

Ahí podría quizás encontrarse el "daño" particular de una política feminista que se vuelve incómoda y también comprometida con la alteridad desde las figuras de un activismo híbrido entre lo teórico y ficcional, que sepa comprender la configuración del espacio común como una figuración múltiple y no clausurada.

Deberíamos urgentemente desviar esos marcos de comprensión para asegurar que no es ni la esencia ni "el hombre de referencia" quienes nos permiten en un mundo plagado de certezas basadas en datos empíricos, dotarnos de la capacidad de ver también los signos y las metáforas que subyacen en esos mismos resultados, para así ampliar nuestra comprensión del mundo y sus fenómenos, integrando lecturas que beneficien en la desviación de esa mirada positivista una interpretación de los signos sociales que la ciencia y en especial los científicos pretenden obstinadamente anular o no integrar. Esto debido principalmente a la insistencia en un lenguaje universalista y no contaminado, que pretende ser exacto sin cuestionar la localidad de sus resultados, el proceso de su ejecución. Existe aquí un punto que quisiera realzar con respecto a los mismos planos de visión que 
clasifican y norman. Pretender cuestionar qué o cómo vemos me parece una necesidad radical, que permite comprender de qué forma vamos a incluir en el análisis de la visión totalizante una discusión sobre lecturas contextuales, como en este caso, la imagen política del feto.

Trabajar en los territorios de la visión es acercarse, en este contexto a discusiones que nos permitan transitar o que muestren una interrupción a las formas tradicionales del conocimiento, para permitir un desvío óptico de la normalización de la pureza clasificatoria del saber académico, donde una intervención en estos planos es un gesto político. Comparto la interrogación que se hace Nelly Richard al preguntarse “¿Cómo no va a ser político elegir lo "universitario" como territorio de intervención si, en el interior de las universidades, los programas de estudio de las facultades y las escuelas dictan las reglas y métodos que norman la pureza epistemológica del conocimiento, la finalidad educativa de las investigaciones en función de un canon de autoridad superior que, en las ciencias y la filosofía, habla en nombre de lo "exacto", lo "verdadero" y lo "universal"? Este es justamente el canon que desacredita los saberes que Michel Foucault llamaba "saberes bajos o inferiores" en tanto saberes "locales, discontinuos, no centralizados, diferenciales, incapaces de unanimidad" (Richard, 159-178).

\section{Imágenes, fotografías y registro biológico}

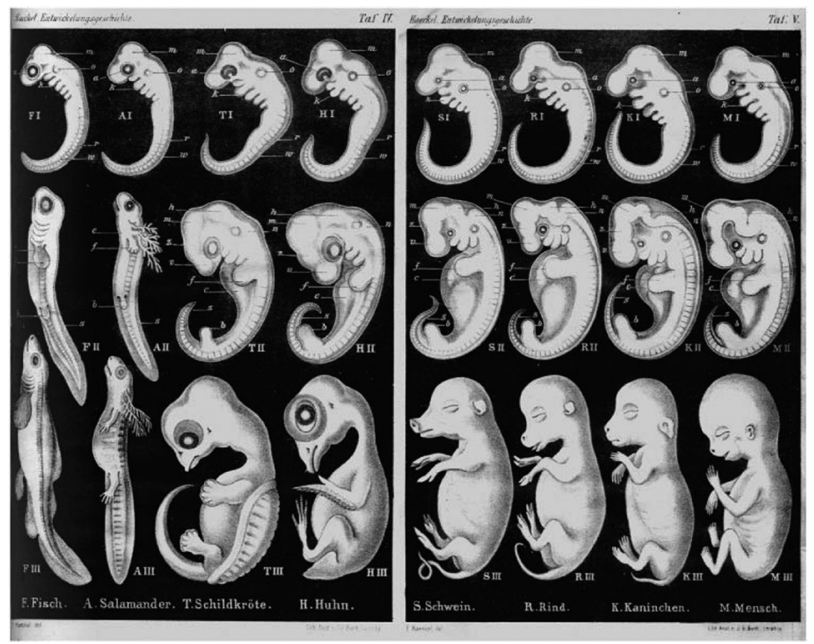

I: Imágenes realizadas por Heackel en 1874 donde es posible apreciar reproducciones de las ocho especies en comparación a las tres etapas de desarrollo. De izquierda a derecha: salamandra, tortuga, pollo, cerdo, vaca, conejo y humano. Tomado de Biological Reviews, Vol. 77, No. 4. (2002) 516. Cambridge Philosophical Society (2002-03-08) 
El biólogo Ernest Haeckel fundó para cierta escuela evolucionista el marco para entender las hipótesis del "ancestro común" y de casi todas las teorías que repletan el conocimiento científico que busca en esos postulados la recapitulación a la "esencia", lo "único" y lo "mítico" estableciendo el árbol de clasificaciones que, junto con el registro fósil, le permitió esclarecer una supuesta historia evolutiva coherente donde las miles de ramificaciones de especies y organismos por muy diversas, variadas o alejadas temporalmente estén siempre enraizadas a un fuerte tronco primario. Haeckel quería explicar en su famoso postulado "la ontogenia siempre recapitula a la filogenia" que la historia individual de todo organismo siempre está sujeta y es producto del trabajo simultáneo que atávicamente ha hecho la especie para mantenerse y adaptarse al medio en el cual se desenvuelve, a su historia y sus relaciones. ¿Cómo pudo haber llegado a tal conclusión? Viendo imágenes. Toda esta teoría está basada en una ordenada disposición de imágenes de diferentes estados embrionarios de organismos como pollos, conejos, humanos y peces en donde se exponen sus relaciones de similitud y diferencias, según los planes de desarrollo embrionario de cada taxón estudiado. En las láminas de Heackel se propone mirar al unísono todas las diversas formas adquiridas por los organismos en un tiempo determinado, agudizando el ojo para ver cierta similitud morfológica en las etapas primarias, cuestión que comprueba una hipótesis unificadora entre los taxones. Todo esto gracias a las supuestas disposiciones que traen las imágenes como reproducción de lo real, como mímesis del mundo. Heackel quizás comprendía la importancia de trabajar con imágenes para establecer los principios que permitieron en su época traducir su realidad, siempre con la pulsión de la clasificación. Gracias a estas imágenes y su ordenamiento dentro de los registros biológicos, lo que sumado a los cambios que la genética molecular y sus análisis filogenéticos han aportado, esclarece cómo se han establecido las conexiones sobre los principios de la ontogenia que llegan directamente como soporte y principio sobre los orígenes y su supuesta recapitulación: como si cada uno llevara como impronta asfixiante siempre la historia de todos en su propio cuerpo. Un cuerpo cuya propiedad está siempre en entredicho.

Imágenes que cambian la perspectiva de la comprensión, de las realidades y los contextos. La potencia de las imágenes que nos 
muestran a la vez movilidad y relación nos permiten traducir los esquemas visuales de un tiempo particular y su entrecruzamiento político y social, pero también nos permiten establecer marcos de lecturas abiertos a ser disgregados por restricciones múltiples y no protocolizadas donde incluir miradas sospechosas del canon.

Miradas como las de la ensayista y artista Susan Sontag, cuya obra está dedicada a escudriñar los efectos políticos y sociales que se encuentran en las imágenes, tomando distancia de ciertas lecturas mas bien tradicionales. Sontag administraba en sus análisis una parcialidad que incluía desde los movimientos de cámara hasta los reclamos y desacuerdos éticos que se encontraban en las imágenes, preguntándose por ejemplo, por qué para el gobierno de Estados Unidos era más importante el registro de las torturas efectuadas por parte de soldados estadounidenses durante la ocupación a Irak el año 2004, que las torturas mismas. En sus textos más que nada, está esa duda. Una duda cuyo soporte de imágenes se encuentra en el registro fotográfico, en su poder corrosivo como fuerza anarquista que puede, en estos casos, desestabilizar el orden administrativo de un país y su organización estatal. En definitiva, su imagen. Ya no es necesariamente la tortura, la humillación, la obscenidad o el sadismo de los gobernantes, sino que el registro de esa tortura, de esa humillación, de esa obscenidad o sadismo de los gobernantes lo que tiene la capacidad de cambiar el plano de la administración y la respuesta. Judith Butler, de hecho nos recuerda que:

la cuestión concreta que preocupaba a Sontag, no obstante, tanto en Sobre la Fotografía como en Ante el dolor de los demás, era saber si las fotografías aún tenían el poder -o si lo habían tenido alguna vez- de comunicar el sufrimiento de los demás, de manera que quienes las miraran pudieran verse inducidos a modificar su valoración política de la guerra (101).

Si estamos de acuerdo con Sontag sobre la valoración política y la posibilidad de implicación social y afectiva que tienen las fotografías podemos preguntarnos: ¿Qué nos muestran entonces estas imágenes de fetos exhibidas cuantiosamente en las pantallas de hospitales reproducidas a nivel mundial? ¿Cómo mirar estas fotografías que son el producto del choque fotoeléctrico de millares de electrones con una superficie que anida un feto que se enjuaga en su 
líquido amniótico? ¿Cómo mirar estas ecografías de fetos reproducidas por una tecnología audiovisual en cuyas imágenes se conectan debates tan polémicos y necesarios como el derecho al aborto y el estatuto de lo "humano"?

Mi análisis, disperso e incompleto, está atravesado por una búsqueda que va desde los estudios de la estética de la fotografía, la teoría feminista y los análisis biológicos de un sujeto que estudia ciencia, siempre extrañándose que la genética no se cuestione su propia utopía biomédica, donde por ejemplo el libro de bases nitrogenas que fue el resultado del proyecto genoma humano, una vez leído no pudo ser completamente comprendido debido quizás a la falta de una secuenciación que incluyera las características móviles de un soporte dinámico como es el material genético, permitiéndose incluir las fallas geográficas de una estructura que no es solo un código estructurado de azúcares y moléculas. Me interesa socavar en aquellos planos de veracidad que implican a la ciencia y la medicina con discusiones que intenten hibridar y contaminar con el "anhelo" $^{\prime 4}$ de transitar críticamente los territorios. El ojo de mi análisis pretende engañar las mismas epistemologías que la ciencia necesita cuando miramos un resultado, cuando utilizamos la estadística o cuando ordenamos por parámetros, haciendo pasar los datos o las experiencias por protocolos de significancia y claridad, de precisión y exactitud. La mirada disidente o el ojo desacatado trata ahí donde lo autoevidente deja de ser natural y se da la posibilidad de restarse de la mirada positivista de la clasificación, tratando de elaborar no lecturas "otras" o "fuera de" sino que se instala en la retina social de lo "ya dicho" para sobrepasar esos contextos.

Mientras realizaba este texto recibí imágenes de muchas mujeres que me enviaron sus ecografías de la misma manera que me enviarían las fotografías de sus hijos. En la mayoría de ellas solo puedo distinguir translúcidas figuras en tonos de grises que representan difuminadamente figuras antropomórficas como resultado de una tecnología electrónica que permite imprimir las imágenes que reproduce la pantalla del computador. Todas estas mujeres me entregaron datos de las fechas de las ecografías, de las medidas anatómicas o de lo mucho que se parecía este registro de sus fetos a sus hijos una vez nacidos, de los rasgos en comunes con su familia, con sus parientes. Escribían con emoción ante el retrato de sus fetos detallándome con 
precisión el momento en el cual descubrieron su sexo y descartaron gracias a parámetros métricos enfermedades como el síndrome de down o labio biselado, entre otras. Una fotografía biomédica que responde a una intervención óptica y electromagnética sobre el cuerpo gestante con una tecnología cada vez más definida donde es posible apreciar no solo la difusión de escalas de grises, sino una imagen que representa nítidamente el supuesto registro de un cuerpo, es decir, su potencia de existencia. Me llaman profundamente la atención las imágenes del ultrasonido que quieren insistentemente encontrar ese rostro de los fetos en gestación, un rostro algo desaparecido en las intervenciones médicas sobre los cuerpos. En estas imágenes veo rostros algo atormentados por una tecnología que insiste en una percepción que recortada del registro estético, insiste en lo vibratorio de la técnica para entregar una fotografía con tonos de hiperrealismo sin interesarse en el desajuste que pareciera observarse. Es la cara incómoda y siempre dubitativa que no quiere exponerse por un puro deseo de visibilidad, sino todo lo contrario: son los rostros que sospechan de la claridad completa del registro, con ese deseo de interrupción que atravesado por contextos de clase, raza y sexo busca un registro desajustado de las maneras de retratar.
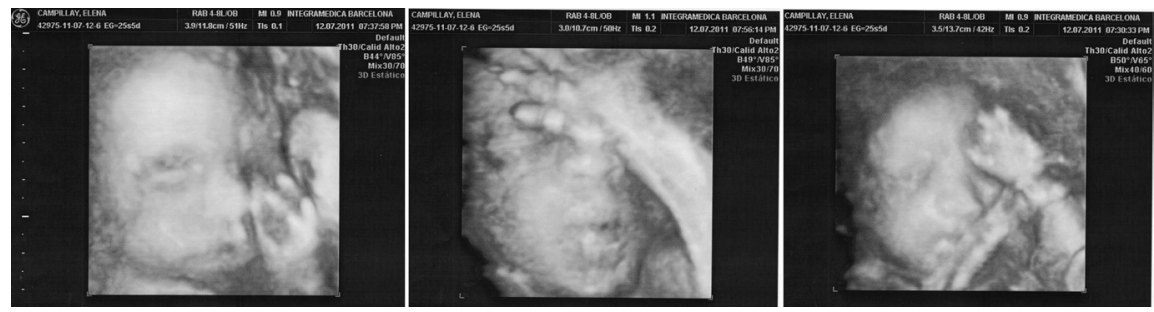

II: Imágenes ecográficas en alta definición enviadas a mi correo electrónico por Luis Venegas. Ellas fueron a su vez enviadas anteriormente por una amiga de Luis. Son ecografías producto de una nueva tecnología de amplia resolución realizadas en Barcelona en julio del 2011.

La búsqueda de miles de rostros de fetos que más que aparecer, generalmente desparecen al igual que los cuerpos de mujeres e inmigrantes nos remite a territorios donde transitar sabiendo que como nos recuerda la teórica feminista Donna Haraway: 
Entidades discursivas y encarnadas como el feto, la inmigrante embarazada y la persona homosexual no son sujetos de cuestiones "sociales", en contraste con cuestiones de estado "políticas" y políticas públicas. Lo queer, al igual que el embrión o feto y la embarazada "indocumentada", está en el corazón de las disputas por reconfigurar de manera precisa el espacio público $(2004,221)$.

Una fotografía de un feto retratado nos abre posibilidades de lectura que se amplían a considerar la técnica fotográfica y su estatuto de arte, la relación de ese registro de cuerpo y sus implicancias sociales como también la ética que subyace en esas pantallas. Considero que si bien la relación que hacemos entre imagen y fotografía no es directamente proporcional o completamente equivalente, existe entre ambos una línea divisoria técnica y artística que debiéramos considerar. "Imagen" siempre habla de una configuración o construcción mutada, que cambia y que se ajusta a diferentes ejes de entendimiento y raciocinio de lo representado e imaginado dependiendo del contexto histórico y filosófico. "Imagen" quizás habla también de un algo más abstracto. Sin embargo de lo que estamos hablando es de la imagen de un cuerpo, de un cuerpo que está en los límites de lo que consideraremos como humano o como "no humano". De la ficcionalización de un registro que representa algo así como "un cuerpo", desencializando ciertas miradas completas y trabajando en el fragmento, en la parte, en el recorte de ese plano. Hablamos en este caso de fotografía necesariamente debido a las posibilidades que entrega como soporte visual la imagen captada por una cámara, pero también por su intervención dentro del régimen estético. ¿Cómo hablar de fotografía en medicina? ¿Por qué integrar una valoración artística a registros técnicos? Hablamos de fotografía principalmente por ese complejo desajuste que compromete a una imagen a estar en ese espacio repartido entre técnica y estética. Como técnica, representa una lógica positiva de un dato logrado mediante mecanismos racionales. Como estética, interviene un imaginario registrado que responde a situaciones contextuales, a una "revolución de los sentidos". La fotografía se aleja de las otras artes de la imagen (la pintura, la escultura) gracias a la posibilidad de cambiar de los "grandes acontecimientos y personajes a la vida de los anónimos, encontrar los síntomas de un tiempo, de una sociedad 
o de una civilización en los detalles ínfimos de la vida ordinaria, explicar la superficie por las capas subterráneas" (Rancière, 2009, 40). Hablamos de una imagen del feto como fotografía debido entonces a las posibilidades políticas que vemos en ello, por desajustar una técnica mecánica y darse la posibilidad de ver la politicidad que está ahí. En definitiva, para ampliar los modos de comprensión de esa imagen y su relación problemática con los imaginarios del cuerpo de las mujeres.
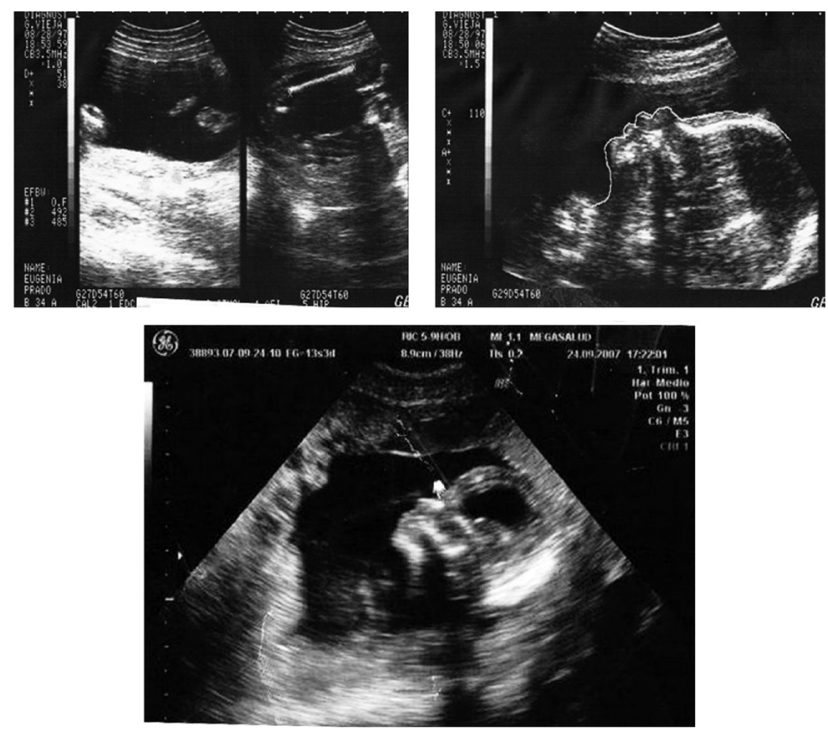

III: Imágenes ecográficas enviadas como archivos adjuntos a mi correo electrónico donde es posible apreciar la delimitación del contorno y la señalización de diferentes estructuras del rostro representado en las ecografías.

Agradezco espacialmente a Naomi Orellana y Eugenia Prado por enviarme estas imágenes.

Los intentos por analizar estas imágenes buscan insistentemente en desplazar un formato netamente objetual del registro-técnico y darse la posibilidad de interrumpir críticamente la fotografía incorporando vectores políticos de una estética que permita leer con un margen más amplio, que la sola disciplina o el solo descubrimiento en las reproducciones de fetos animadas en la tecnología médica. 


\section{Traiciones genéticas}

Desde el primer caso considerado como eritroblastosis fetal ${ }^{5}$ (una extraña enfermedad que involucra la producción de anticuerpos por parte de la denominada "gestante" al embrión en desarrollo, considerándolo un organismo extraño hasta el punto de expulsarlo del cuerpo) pareciera que ciertos abortos perdieron su categoría de desconfianza bioética al reproducir un comportamiento "natural". Esto debido a su inclusión dentro de enfermedades que reconoce el aparato biomédico a nivel "universal", es decir, en cuanto la interrupción de la gestación adquirió los estatutos de "natural" o "universal" el proceso fue descalzado de toda represión ética y social. De esta forma, esta "falla" de lo genético adquirió una inmunidad social por el hecho de recibir un rótulo, de ser nombrada desde un aparato médico externo que si bien tiene un directo correlato con un "interior" somático, no posee las cualidades que particularizan la intervención personal sobre la biología reproductiva ("me hice un aborto") pues la designación patológica desliga completamente las responsabilidades corporales argumentando un "así lo quiso la naturaleza". Con esto quiero decir un asunto bastante claro y categóri$\mathrm{co}$, para lo cual la eritroblastosis fetal me acompaña en su proceso de conformación como patología, esto es, que existieron -y siguen existiendo- "abortos" que dejaron de considerarse como tal en cuanto se descubrió (descubrir como sinónimo de crear, como clave cifrada que construye realidad) la categoría de "enfermedad" que dio la explicación a las expulsiones de tejidos embrionarios lo que permitió en primer caso, la pérdida total de sospecha de qué comieron, cómo comieron o qué introdujeron a sus cuerpos estas mujeres durante todo el tiempo que duró la gestación, deshaciéndose así de toda responsabilidad social, ya que es el dispositivo biomédico quien desde ahora responde por ella. Un dispositivo que en sus múltiples actualizaciones y propuestas intenta dar coherencia a un discurso en el cuerpo, cuya regulación está en el centro de su interés por tratarse justamente de aquello donde lo simbólico y lo material conviven mutualistamente. Que la eritroblastosis fetal sea, como toda patología, un terreno donde convive el cuerpo y el discurso médico que integra y relega ciertos síntomas, nos lleva necesariamente a un análisis que traslada la discusión sobre la misma pertenencia del cuerpo y las posibilidades de 
intervención sobre él. Sobre cómo la constitución de una patología puede cambiar los planos morales de aceptación donde justamente la medicina dictará los patrones de salud regulando la clasificación del estatuto corporal. La sentencia feminista "Mi cuerpo es mío y yo decido sobre él" pareciera que entra en crisis en casos como éste al interrumpir en la plasticidad misma de un cuerpo que no siempre es propio. La filósofa Catherine Malabou nos recuerda que:

Hoy la globalización fija por todos lados umbrales de transformación. En un sistema cerrado, la transformación in situ es la única posibilidad dinámica. Este hecho justifica la más grande de las explotaciones y alienaciones. En efecto, es muy fácil considerar que los sujetos son materias blandas susceptibles de ser plegadas en cualquier sentido y tantas veces como sea necesario (....) importa entonces estar muy atentos a las modalidades precisas de la transformación y a introducir diferencias finas entre dichas modalidades (2011, 36).

Cabe preguntarse ¿Qué es lo que hace al cuerpo? ¿Cuáles son los mecanismos que restringen la existencia del cuerpo, el cuerpo propio? Pareciera que la atención en la elaboración de un lenguaje para denominar al cuerpo se ha hecho una estrategia donde estar atento. Ejemplo de esto es lo que conocemos cuando el cuerpo no responde a los protocolos de normalización y disciplinamiento que otorgan, a través del lenguaje, categorías de finitud discreta. Son éstas las categorías en las que se requiere intervenir críticamente y dar la posibilidad de integración para que la aparición de los cuerpos refleje, en cierto sentido, una política que integre lo hasta ahora irrepresentable de las rotundas divisiones disciplinarias.

Quizás ajustar una visión que se desapegue de la seguridad de la clasificación, es tener la posibilidad de no mirar o mirar de reojo los desencuadres que se patentan en imágenes biopolíticas que intentan no encontrar una identidad, sino en develar los procesos de construcción de esa supuesta "realidad" que predomina aún con prepotencia las prácticas del saber/poder.

\section{Epílogo: la imagen de un feto}

Retratar en imágenes un feto es un gesto que nace justamente ahí donde estos tejidos y palpitaciones líquidas no son ni solo pose, 
ni solo registro de un momento porque alteran el orden estético de lo establecido, del retrato cotidiano de lo que quizás no es ni vida, ni esencia. La vida es hoy más que nunca un registro de esa vida. Vivimos registrando compulsivamente lo que vivimos. Como si un bostezo al despertarse no fuera solo eso, sino un registro estético de eso mismo. Se nos dice que la fotografía es pura instantaneidad, pura fugacidad, pura inmanencia. Pero no. Lo que uno mira, lo que cree ver, también te mira, te observa. Y eso está porque uno comprende dentro de un marco de representación, porque las imágenes adquieren compromiso. Creo que estas fotografías, estas imágenes de cientos de embriones, fetos y neonatos trabajan desde lo que falta, desde lo que no está, lo que no las completa. Y ahí está, para mí, su mayor fortaleza. En trabajar en esas zonas que siempre faltan, que siempre carecemos. En esos lugares en los que uno vive todos los días.

\section{Notas}

1 En este contexto, es importante mencionar las diferencias que existirían al recurrir a los signos "mujer" y "mujeres". Teresa de Lauretis dice "Con la 'mujer' hago referencia a una construcción ficticia a un destilado de discursos, diversos pero coherentes, que dominan a las culturas occidentales (discursos críticos y científicos, literarios o jurídicos), que funciona a la vez como su punto de fuga y su parcial condición de existencia (.... ) Con 'mujeres', por el contrario quiero referirme a los seres históricos que, a pesar de no poder ser definidos al margen de estas formaciones discursivas, poseen, no obstante una existencia material evidente". (De Lauretis, 15-16).

2 Rojas, Sergio. "Identidad y Disidencia". Texto de presentación del libro Por un feminismo sin mujeres leído el 2 de junio de 2011 en el Museo de la Solidaridad Salvador Allende.

3 Dentro de esta teoría feminista contemporánea habría que señalar autoras que son -según mi óptica- fundamentales para comprender las teorizaciones y críticas que ha establecido el feminismo: Donna Haraway, Teresa de Lauretis, Judith Butler, Rossi Braidotti, Catherine Malabou, Genevieve Fraise, Gloria Anzaldúa, Nelly Richard, Alejandra Castillo, Valeria Flores, Marta Lamasy Beatriz Preciado.

4 Abogo siempre por una política desde la imagen de un "anhelo" sin esperar una seguridad coherente de la lucha misma. Pero anhelo no significa la pura fugacidad de un "puede ser" sino que en el anhelo se incluye firmemente las posibilidades de una realización. "Anhelo" habla de lo que siempre queda fuera, de lo que no podemos incluir, pero por lo que debemos luchar y trabajar desde múltiples lugares y espacios. Siempre habrá algo que queda fuera, que 
no se alcanza a ver en los marcos de visualidad. La micropolítica trabaja en ese lugar.

5 El primer caso de Eritroblastosis fetal fue descubierto el año 1941 por los investigadores Levine y Katzin quienes teniendo en consideración los conocimientos acumulados en el ámbito de la hematología y las posibilidades combinatorias de los grupos sanguíneos, entendieron que esta "incompatibilidad" se debía a diferencias en los factores hematológicos de la madre y el hijo, lo que llevaba a la expulsión del feto. Sin embargo, el descubrimiento de esta patología no fue algo fácil pues el año 1945 Coombs, Race y Mourant descubrieron en casos en los cuales tanto madres como hijos poseían los mismos grupos sanguíneos que seguía existiendo esta "incompatibilidad" lo que de igual forma desencadenaba en un aborto y la muerte del feto. El arduo trabajo de los investigadores permitió completar la descripción de la patología al crear el "test de antiinmunoglubulina humana" con el cual se detectó que más que la incompatibilidad sanguínea el problema estaba dado por la producción de anticuerpos que realizaba la misma madre sobre las células del tejido embrionario, considerándolo extraño o falso, lo que cambió totalmente la discusión biocientífica sobre la etiología de la enfermedad, llevándola ahora a los terrenos de la inmunología. (Levine y Katzin, 2006)

\section{Bibliografía}

Butler, Judith. Marcos de Guerra. Las vidas lloradas. Madrid: Editorial Paidòs, 2010.

De Lauretis, Teresa. Alicia ya no: feminismo, semiótica, cine. Madrid: Ediciones Cátedra, 1992.

Esposito, Roberto. Inmunitas. Buenos Aires: Amorrortu Editores, 2002.

Flores, Valeria. Industrias del Cuerpo. Presentado en Tercer Circuito Disidencia Sexual "No hay Respeto". Santiago: CUDS/ Universidad de Chile/Universidad ARCIS, 2011.

Haraway, Donna. Testigo_Modesto@Segundo_Milenio.HombreHembra@_Conoce_Oncoratón®. Feminismo y tecnociencia. $1^{\text {a }}$ ed. Barcelona: Editorial UOC, 2004.

Levine P, Katzin E M., et al. Isoimmunization in pregnancy, its posible bearing on the etiology of erythroblastosis fetalis, JAMA 1941:116-825. May Wewers J, Kaiser JR, Moore EK, Blackall DP. Severe neonatal hemolysis due to a maternal antibody to the low-frequency Rh antigen C(w). Am J Perinatol. 2006 May;23(4):213-7.

Malabou, Catherine. La plasticidad en espera. Santiago: Editorial Palinodia, 2011.

Rancière, Jacques. El reparto de lo sensible. Santiago: Editorial Lom, 2009.

Richard, Nelly. “Deseos de... ¿Qué es un terreno de intervención política?”. En Por un feminismo sin mujeres. Santiago: Territorios Sexuales Ediciones/CUDS.

Rojas, Sergio. Identidad y Disidencia. Texto de presentación del libro Por un feminismo sin mujeres leído el 2 de junio de 2011 en el Museo de la Solidaridad Salvador Allende. 
